\title{
Impact of Low-Cost Point-of-Use Water Treatment Technologies on Enteric Infections and Growth among Children in Limpopo, South Africa
}

\author{
Courtney L. Hill, ${ }_{7}^{1}$ Kelly McCain, ${ }^{1,2}$ Mzwakhe E. Nyathi, ${ }^{3}$ Joshua N. Edokpayi, ${ }^{4}$ David M. Kahler, ${ }^{5}$ Darwin J. Operario, ${ }^{6}$ \\ David D. J. Taylor, ${ }^{7}$ Natasha C. Wright, ${ }^{8}$ James A. Smith, ${ }^{1}$ Richard L. Guerrant, ${ }^{6}$ Amidou Samie, ${ }^{9}$ Rebecca A. Dillingham, ${ }^{6}$ \\ Pascal O. Bessong, ${ }^{9 *}$ and Elizabeth T. Rogawski McQuade ${ }^{6,10 *}$ \\ ${ }^{1}$ Department of Engineering Systems and Environment, University of Virginia, Charlottesville, Virginia; ${ }^{2}$ Department of Epidemiology, Rollins \\ School of Public Health, Emory University, Atlanta, Georgia; ${ }^{3}$ Department of Animal Science, University of Venda, Thohoyandou, South Africa; \\ ${ }^{4}$ Department of Hydrology and Water Resources Mining and Environmental Geology, University of Venda, Thohoyandou, South Africa; ${ }^{5}$ Center for \\ Environmental Research and Education, Duquesne University, Pittsburgh, Pennsylvania; ${ }^{6}$ Division of Infectious Diseases and International Health, \\ University of Virginia, Charlottesville, Virginia; ${ }^{7}$ Department of Civil and Mineral Engineering, University of Toronto, Toronto, Canada; ${ }^{8}$ Department \\ of Mechanical Engineering, University of Minnesota Twin Cities, Minneapolis, Minnesota; ${ }^{9}$ Department of Microbiology, University of Venda, \\ Thohoyandou, South Africa; ${ }^{10}$ Department of Public Health Sciences, University of Virginia, Charlottesville, Virginia
}

\begin{abstract}
Enteric infections early in life have been associated with poor linear growth among children in low-resource settings. Point-of-use water treatment technologies provide effective and low-cost solutions to reduce exposure to enteropathogens from drinking water, but it is unknown whether the use of these technologies translates to improvements in child growth. We conducted a community-based randomized controlled trial of two water treatment technologies to estimate their effects on child growth in Limpopo, South Africa. We randomized 404 households with a child younger than 3 years to receive a silver-impregnated ceramic water filter, a silver-impregnated ceramic tablet, a safe-storage water container alone, or no intervention, and these households were followed up quarterly for 2 years. We estimated the effects of the interventions on linear and ponderal growth, enteric infections assessed by quantitative molecular diagnostics, and diarrhea prevalence. The silverimpregnated ceramic water filters and tablets consistently achieved approximately 1.2 and 3 log reductions, respectively, in total coliform bacteria in drinking water samples. However, the filters and tablets were not associated with differences in height (height-for-age $z$-score differences compared with no intervention: $0.06,95 \% \mathrm{Cl}:-0.29,0.40$, and 0.00, 95\% Cl: $-0.35,0.35$, respectively). There were also no effects of the interventions on weight, diarrhea prevalence, or enteric infections. Despite their effectiveness in treating drinking water, the use of the silver-impregnated ceramic water filters and tablets did not reduce enteric infections or improve child growth. More transformative water, sanitation, and hygiene interventions that better prevent enteric infections are likely needed to improve long-term child growth outcomes.
\end{abstract}

\section{INTRODUCTION}

In low-resource settings, lack of safe water has long-term detrimental consequences for child health and development. Exposure to enteropathogens in contaminated drinking water not only causes enteric infections and diarrhea but also may contribute to environmental enteropathy, an inflammatory condition of the gut associated with increased intestinal permeability, impaired gut immune function, and malabsorption. ${ }^{1}$ The cumulative impact of this exposure has been associated with poor linear growth and stunting, ${ }^{2,3}$ which affects approximately 162 million $^{4}$ or $27 \%$ of children ${ }^{5}$ younger than 5 years globally. Stunting early in life has been associated with cognitive impairment, poor school performance, low adult economic productivity, and increased risk of chronic disease later in life. . $^{6,7}$

In 2012, the WHO adopted a resolution with a global target to reduce the number of stunted children younger than 5 years by $40 \%$ by $2025 .{ }^{6}$ Interventions to improve water, sanitation, and hygiene (WASH) were identified as an essential component of efforts to reach this goal. ${ }^{3}$ The first 2 years of life are a critical period and provide the optimal window to prevent child stunting. ${ }^{6,7}$ However, until the recently published WASH Benefits ${ }^{8,9}$ and The Sanitation, Hygiene, Infant Nutrition Efficacy $(\mathrm{SHINE})^{10}$ trials, few WASH

*Address correspondence to Elizabeth T. Rogawski McQuade, Department of Public Health Sciences and Division of Infectious Diseases \& International Health, University of Virginia, P.O. Box 801379, Charlottesville, VA 22908, E-mail: etr5m@virginia.edu or Pascal O. Bessong, Department of Microbiology, University of Venda, Private Bag X5050, Thohoyandou, ZA 0950, E-mail: pascal.bessong@ univen.ac.za. intervention trials examined child growth as a primary outcome or assessed enteric infections, an important marker of the interruption of fecal-oral microbial transmission. Earlier studies have focused mainly on caregiver-reported diarrhea, which is subject to recall bias. ${ }^{11}$ Interventions that improve access to safe water have the potential to make an impact on child growth and enteric infections, but have not been well studied toward this aim.

Strategies to increase access to clean water are challenged by recontamination between water collection and use. ${ }^{12}$ Pointof-use (POU) water treatment technologies treat drinking water in the household before it is consumed, eliminating the risk of contamination both at the source and during transport to the household. ${ }^{13,14}$ Sustainable, socially acceptable, and low-cost interventions with these technologies have the potential to improve the microbial quality of household water, reduce pathogen exposure to children, and prevent diarrheal diseases. ${ }^{15-18}$

Our research team has participated in the development and implementation of two POU water technologies that have demonstrated technical efficacy, sustainability, and social acceptance in low-resource communities. The first, a silverimpregnated ceramic water filter, is a well-developed, tested, and widely used device. ${ }^{19,20}$ In addition to mechanically removing turbidity and pathogens, the filter is treated with silver to kill live pathogens that pass through the filter and to provide residual disinfectant to reduce risk of recontamination after treatment. Silver-impregnated ceramic water filters can be more cost effective, exhibit lower environmental impacts (e.g., energy consumption and global warming potential), and show more potential for quality of life improvement than centralized water treatment and distribution systems. ${ }^{21}$ 
The second technology is a silver-impregnated ceramic tablet (MadiDrop ${ }^{\mathrm{TM}}$, Silivhere Technologies, Inc., Charlottesville, VA). ${ }^{22,23}$ When the ceramic tablet is placed in a household water storage container, silver diffuses through the porous ceramic into the water at a release rate that is effective for continual disinfection of waterborne pathogens while remaining below the silver drinking water standard. The tablet is effective for daily treatment of $10 \mathrm{~L}$ over 24 hours for at least 6 months. It can be used alone or in combination with a water filter, which may be most effective in situations with high water turbidity.

Both technologies have proven to be highly effective in treating water, showing up to a 3.2 log reduction in total coliform bacteria during field studies in South Africa and Tanzania. ${ }^{23,24}$ Ceramic water filters also reduced diarrheal rates among HIV-positive individuals in Limpopo, South Africa, by $79 \% .{ }^{15}$ However, it is unknown whether the use of these technologies can translate to improvements in child health outcomes, particularly linear growth. We conducted a community-based randomized controlled intervention trial to estimate the effectiveness of the silver-impregnated ceramic water filter and the silver-impregnated ceramic tablet to improve child growth in Limpopo, South Africa.

\section{METHODS}

Participants. Eligible households were identified in rural villages in the Dzimauli community in Limpopo, South Africa, between June and November 2016. Field-workers took a census of the villages by visiting each house to determine whether the household met the inclusion criteria for the study: mother was in the third trimester of pregnancy or there was at least one child younger than 3 years in the household. Households were excluded if they had chlorinated water piped into the home or routinely delivered (via truck or diversion) to a permanent, engineered system that stored the water within the property, they used a ceramic filter or other commercial water treatment system (including a permanent, engineered system that treats the water through filtration and/or chlorination), they had plans to move outside the community in the next 6 months, the child's caregiver was younger than 16 years or unable to give consent, or the youngest child aged less than 3 years was seriously ill (had a severe disease requiring prolonged hospitalization or a severe or chronic condition diagnosed by medical doctor, e.g., neonatal disease, renal disease, chronic heart failure, liver disease, cystic fibrosis, and congenital conditions). If eligible, caregivers were asked to participate, and written informed consent was obtained.

The study protocol was approved by the University of Virginia Institutional Review Board for Health Sciences Research (18662) and the University of Venda Research Ethics Committee (SMNS/15/MBY/27/0502). This study was registered at clinicaltrials.gov (NCT03012048).

Interventions. Enrolled households were randomized to receive the following: 1) a silver-impregnated ceramic water filter inside a 20-L safe storage container (covered plastic bucket with a spigot) with two silver-impregnated ceramic tablets in the lower reservoir, 2) two silver-impregnated ceramic tablets inside a 20-L safe storage container, 3) a safe storage container alone, or 4) no intervention. The safe storage container alone arm was included to estimate the effectiveness of a designated, covered container for clean drinking water that limits recontamination from dirty hands. Randomization was stratified by the age (011 months, 12-23 months, and 23-35 months) of the youngest child in the household aged less than 3 years (henceforth, primary study child) and was conducted in blocks of 4 . Details for preparation of each intervention and instructions given to participants have been described. ${ }^{25-29}$

Because the silver-impregnated ceramic tablet was designed to treat $10 \mathrm{~L}$ of water, two tablets were initially chosen to treat water in the 20-L container. During follow-up, the silver concentration in some treated water samples exceeded the WHO drinking water recommended guideline value of $100 \mu \mathrm{g} / \mathrm{L}$ silver. $^{30}$ In coordination with our data safety and monitoring committee, we made several modifications to the interventions to ensure silver concentrations were less than the designated limit. In October 2016, the two silverimpregnated ceramic tablets in the lower reservoir of the storage container were removed from the filter group (1 above), and one silver-impregnated ceramic tablet was removed from the tablet-only group (2 above). In May 2017, the silverimpregnated ceramic tablets were replaced with those that were manufactured with $50 \%$ of the original amount of silver. In August 2017, all silver-impregnated ceramic tablets were replaced with silver-impregnated ceramic filters. In December 2017, all silver-impregnated ceramic filters were replaced with ceramic filters that did not contain silver. ${ }^{25}$ Based on the interventions in place during most of the follow-up, we refer to the interventions for the remainder of the article as 1) a silverimpregnated ceramic water filter, 2) a silver-impregnated ceramic tablet, 3) a safe storage container, and 4) no intervention.

Power calculations. We aimed to enroll at least 400 households (approximately 100 per randomized arm). Assuming a $20 \%$ dropout rate, we expected 320 households (80 per randomized arm) to complete follow-up. Assuming a baseline mean height-for-age $z$-score (HAZ) of -1.67 (the mean HAZ at 2 years in the the Etiology, Risk Factors, and Interactions of Enteric Infections and Malnutrition and the Consequences for Child Health and Development study [MAL-ED] South Africa study), ${ }^{2}$ we would have $80 \%$ power to detect a $27 \%$ difference in $\triangle \mathrm{HAZ}(0.45 \mathrm{z}$-score difference) from baseline to the end of follow-up in pairwise comparisons between intervention and control groups (alpha level of 0.05 and two-sided test). We would have $80 \%$ power to detect a $19 \%$ difference in $\triangle \mathrm{HAZ}$ (0.31 z-score difference) in the comparison that combines the two intervention and two control arms.

Data collection. A baseline visit was conducted to install the interventions and train caregivers on intervention use and maintenance. Field-workers encouraged participants to use the interventions for all drinking water in the household. A baseline questionnaire was conducted concerning demographics, socioeconomic status, water sources, sanitation and hygiene practices, and 7-day diarrhea prevalence in the primary study child. Height and weight were measured, and a stool sample was collected from the primary study child. Length was measured in children younger than 24 months of age using a recumbent measuring board (Seca, Hamburg, Germany), and height was measured in children older than 24 months using a stadiometer. For each measurement, readings were taken twice and the average recorded to the nearest $0.1 \mathrm{~cm}$. Weight was measured with a digital scale (Seca), also taken twice, and the average reported to the nearest $10 \mathrm{~g}$. For quality assurance, the height and weight measurements for a random $5 \%$ sample of participants were repeated by a supervisor.

Field-workers visited households every month for 2 years to ensure the interventions were in working condition and being 
used properly. A short questionnaire was given to caregivers to ascertain adherence to appropriate use of the interventions. Every 3 months, the home visit was extended to measure height and weight and collect a stool sample from the primary study child. A questionnaire was given to caregivers to ascertain water sources and use practices, adherence to the interventions, and for the primary study child: feeding practices, illnesses including diarrhea in the past 7 days, and antibiotic use.

To validate self-reported data on the use of the interventions, at the beginning of the second year of follow-up, we replaced the spigots on the intervention containers with the Smart Spout, a modified spigot with a sensor (an accelerometer, microcontroller, and battery) that measured objective intervention usage based on the duration of each time the spigot was opened. Collection of these data occurred between July 15 and September 15, 2017 by wireless transfer from the spigots to a smart phone.

Microbiologic methods. Stool specimens were stored in frozen unpreserved aliquots at $-70^{\circ} \mathrm{C}$ before testing. DNA was extracted from stool using the Qiagen QIAmp Fast DNA Stool Mini Kit (Qiagen, Hilden, Germany) with a modified protocol as previously described ${ }^{31}$ and tested for enteropathogens using multiplex real-time PCR (LightCycler 480, Roche Applied Science, Penzberg, Germany). Targeted genes for amplification identified enteroaggregative Escherichia coli (EAEC), enterohemorrhagic E. coli/enteropathogenic E. coli (EHEC/ EPEC), Giardia, Campylobacter jejuni/C. coli, Cryptosporidium, enterotoxigenic E. coli, Shigella/enteroinvasive E. coli (EIEC), and adenovirus (Supplemental Table S1). ${ }^{32}$

Microbiological water testing was conducted every 6 months in treated water samples from a random subset of 25 households per intervention group. Membrane filtration was used to enumerate total coliform bacteria and $E$. coli (U.S.E.P.A. method 8074 or 10023). Silver levels in water treated by the silver-impregnated ceramic filters and ceramic tablets were monitored in a random subset of $50-100$ households every 3 months. ${ }^{25}$ Total silver concentration was measured by graphite furnace atomic absorption spectrometry (U.S.E.P.A. method 7010). Details of these methods and the results have been reported previously. ${ }^{25}$

Outcomes. The primary outcome was the change in $\triangle \mathrm{HAZ}$ from baseline to the end of follow-up at 24 months of age $\left(H A Z_{24}\right.$ months $\left.-H A Z_{\text {baseline }}\right)$ in the primary study child. Anthropometric measurements of height and weight were used to construct indices of $\mathrm{HAZ}$, weight-for-height $z$-score (WHZ), and weight-for-age $z$-score (WAZ) using the 2006 WHO child growth standards. ${ }^{33}$ Extreme measurements (identified by the 1st and 99th percentiles of all 3-month changes in z-scores) were excluded. If baseline anthropometry was unavailable, then $\triangle \mathrm{HAZ}$ was calculated as $\mathrm{HAZ}_{24}$ months $-H A Z_{3}$ months.

Secondary anthropometric outcomes included $\triangle W A Z$, and $\triangle \mathrm{WHZ}$, calculated as above and risk of stunting $(H A Z<-2)$ at 24 months. Total coliform bacteria and $E$. coli in household water samples, 7-day prevalence of diarrhea, and prevalence of enteric infections were also secondary outcomes. We assessed the eight pathogens individually as well as a combined metric of the total count of pathogens detected.

Data analysis. The primary analysis was intention-to-treat such that participants were analyzed according to their randomized assignment, regardless of adherence and intervention changes over follow-up. We also conducted a secondary as-treated analysis for the diarrhea and enteric infection outcomes in which participants were analyzed according to the intervention they had at the time of outcome measurement (e.g., participants originally in the ceramic tablet group were included in the filter group after the tablets were replaced with filters).

Baseline household, caregiver, and child characteristics were compared by intervention group and dropout status using descriptive statistics. Adherence to interventions was described based on the self-reported questionnaire data. Households were classified as having objectively used the intervention on a given day if the Smart Spout spigot was held open for at least 5 seconds, which corresponds to approximately $300 \mathrm{~mL}$ withdrawn from the container. We included observations from each group on each day in which at least 33 observations were available to reduce the influence of outlier households.

We compared the primary outcome, $\triangle H A Z$, in pairwise comparisons between the four study groups using linear regression, adjusting for age at baseline using cubic splines with 4 knots. We also estimated effects separately by age-group at baseline. We estimated the effects of the interventions on risk of stunting using log-binomial regression adjusting for age as above and a quadratic term for baseline length-for-age $z$-score. We estimated effects on 7-day diarrhea prevalence at all 3-month follow-up visits and on prevalence of enteric infections at $6,12,18$, and 24 months of follow-up using logbinomial regression adjusting for age and with general estimating equations to account for clustering within repeated measurements from individuals. Estimates for enteric infections were also adjusted for year of stool testing. We conducted a sensitivity analysis in which we excluded samples tested in 2016 and 2017 (15-23\% of all follow-up samples depending on the pathogen) based on higher than expected prevalences among these samples.

For all outcomes, based on our prespecified analysis plan, if there was no evidence of effect heterogeneity between the two intervention groups and two control groups, then we assessed the overall impact of the interventions by estimating effects after combining the intervention groups (tablet and filter) and control groups (safe storage container and no intervention).

\section{RESULTS}

A total of 404 households were enrolled and randomized to receive a silver-impregnated ceramic water filter $(n=102)$, a silver-impregnated ceramic tablet $(n=99)$, a safe storage container $(n=105)$, or no intervention $(n=98)$. Almost all mothers ( $n=390,96.5 \%$ ) completed at least secondary school education and were on average 28 years old (SD: 6.7 ; Table 1). The mean monthly income for the household was 1920 South African Rand (ZAR) (approximately USD135 in June 2016), which is consistent with that of previous studies in the area, ${ }^{24}$ and households had on average 2.4 children younger than 15 years (SD: 1.2). The majority of participants most frequently obtained drinking water from the municipality (piped into their yard, $n=91,22.5 \%$; or from a public stand pipe, $n=77,19.1 \%$ ) or from surface water through a piped system (into their yard, $n=100,24.8 \%$; or from a public stand pipe, $n=46,11.4 \%$ ). Municipal water was generated from a treatment facility that uses standard treatment including chlorine disinfection. However, we have previously shown that 
TABLE 1

Baseline characteristics of 404 enrolled children by intervention group

\begin{tabular}{|c|c|c|c|c|c|}
\hline & Filter $(n=102)$ & Ceramic tablet $(n=99)$ & Safe storage $(n=105)$ & No intervention $(n=98)$ & Overall $(n=404)$ \\
\hline \multicolumn{6}{|l|}{ Demographic/household characteristics } \\
\hline Mother's age (years), mean $( \pm S D)$ & $28.4( \pm 7.1)$ & $27.0( \pm 6.5)$ & $28.2( \pm 6.3)$ & $27.8( \pm 6.8)$ & $27.8( \pm 6.7)$ \\
\hline \multicolumn{6}{|c|}{ Highest school grade level of mother, $n(\%)$} \\
\hline Primary & $4(3.9)$ & $5(5.1)$ & $4(3.8)$ & $1(1.0)$ & $14(3.5)$ \\
\hline Secondary & $61(59.8)$ & $55(55.6)$ & $64(61.0)$ & 57 (58.2) & $237(58.7)$ \\
\hline Matriculation & $24(23.5)$ & $26(26.3)$ & $21(20.0)$ & $26(26.5)$ & $97(24.0)$ \\
\hline Undergraduate & $7(6.9)$ & $10(10.1)$ & $11(10.5)$ & $8(8.2)$ & $36(8.9)$ \\
\hline Postgraduate & $4(3.9)$ & $1(1.0)$ & $5(4.8)$ & $5(5.1)$ & $15(3.7)$ \\
\hline Missing & $2(2.0)$ & $2(2.0)$ & $0(0)$ & $1(1.0)$ & $5(1.2)$ \\
\hline \multicolumn{6}{|c|}{ Highest school grade level of the head of the household, $n(\%)$} \\
\hline None & $6(5.9)$ & $4(4.0)$ & $5(4.8)$ & $6(6.1)$ & $21(5.2)$ \\
\hline Primary & $24(23.5)$ & $26(26.3)$ & $29(27.6)$ & $24(24.5)$ & $103(25.5)$ \\
\hline Secondary & $47(46.1)$ & $52(52.5)$ & $40(38.1)$ & $40(40.8)$ & $179(44.3)$ \\
\hline Matriculation & $16(15.7)$ & $11(11.1)$ & $21(20.0)$ & 19 (19.4) & $67(16.6)$ \\
\hline Undergraduate & $6(5.9)$ & $2(2.0)$ & $6(5.7)$ & $4(4.1)$ & $18(4.5)$ \\
\hline Postgraduate & $3(2.9)$ & $4(4.0)$ & $4(3.8)$ & $5(5.1)$ & $16(4.0)$ \\
\hline \multicolumn{6}{|c|}{ Relationship of the head of the household to the child, $n$ (\%) } \\
\hline Father & $37(36.3)$ & $33(33.3)$ & $38(36.2)$ & $27(27.6)$ & $135(33.4)$ \\
\hline Mother & $15(14.7)$ & $13(13.1)$ & $13(12.4)$ & $21(21.4)$ & $62(15.3)$ \\
\hline Grandmother & $32(31.4)$ & $29(29.3)$ & $32(30.5)$ & $31(31.6)$ & $124(30.7)$ \\
\hline Grandfather & $15(14.7)$ & $24(24.2)$ & $20(19.0)$ & 15 (15.3) & 74 (18.3) \\
\hline Sibling & $0(0.0)$ & $0(0.0)$ & $0(0.0)$ & $1(1.0)$ & $1(0.2)$ \\
\hline Other & $3(2.9)$ & $0(0.0)$ & $2(1.9)$ & $3(3.1)$ & $8(2.0)$ \\
\hline $\begin{array}{l}\text { Socioeconomic status score [WAMI; } \\
\text { mean }( \pm S D)]\end{array}$ & $0.79( \pm 0.11)$ & $0.78( \pm 0.12)$ & $0.78( \pm 0.13)$ & $0.78( \pm 0.11)$ & $0.78( \pm 0.11)$ \\
\hline $\begin{array}{l}\text { Monthly household income (ZAR), } \\
\text { mean }( \pm S D)\end{array}$ & $1,746( \pm 1,154)$ & $1,987( \pm 1,865)$ & $2,300( \pm 3,066)$ & $1,626( \pm 886)$ & $1,920( \pm 1,965)$ \\
\hline $\begin{array}{l}\text { Adults older than } 15 \text { years in } \\
\text { household, mean }( \pm S D)\end{array}$ & $2.9( \pm 1.2)$ & $3.1( \pm 1.6)$ & $3.1( \pm 1.4)$ & $2.9( \pm 1.6)$ & $3.0( \pm 1.5)$ \\
\hline $\begin{array}{l}\text { Children younger than } 15 \text { years in } \\
\text { household, mean }( \pm S D)\end{array}$ & $2.3( \pm 1.0)$ & $2.3( \pm 1.1)$ & $2.5( \pm 1.4)$ & $2.5( \pm 1.2)$ & $2.4( \pm 1.2)$ \\
\hline $\begin{array}{l}\text { Crowded household (>2/room for } \\
\text { sleeping), } n(\%)\end{array}$ & $47(46.1)$ & $47(47.5)$ & $54(51.4)$ & $55(56.1)$ & $203(50.2)$ \\
\hline \multicolumn{6}{|l|}{ Water use practices } \\
\hline \multicolumn{6}{|l|}{ Primary drinking water source, $n$ (\%) } \\
\hline Municipal & $38(37.3)$ & $47(47.5)$ & $39(37.1)$ & $44(44.9)$ & $168(41.6)$ \\
\hline Surface water from tap/pipe & 41 (40.2) & $32(32.3)$ & $41(39.0)$ & $32(32.7)$ & $146(36.1)$ \\
\hline Directly from surface water & $7(6.9)$ & $5(5.1)$ & $9(8.6)$ & $6(6.1)$ & $27(6.7)$ \\
\hline Groundwater & $11(10.8)$ & $15(15.2)$ & $10(9.5)$ & $12(12.2)$ & $48(11.9)$ \\
\hline Unknown/other & $5(4.9)$ & $0(0.0)$ & $6(5.7)$ & $4(4.1)$ & $15(3.7)$ \\
\hline $\begin{array}{l}\text { Length of time to collect water } \\
\text { (minutes), mean }( \pm S D)\end{array}$ & $24.6( \pm 43.2)$ & $31.2( \pm 57.9)$ & $26.9( \pm 43.3)$ & $24.4( \pm 34.8)$ & $26.7( \pm 45.4)$ \\
\hline \multicolumn{6}{|c|}{ Typical point-of-use drinking water treatment, $n(\%)$} \\
\hline Let stand and settle & $2(2.0)$ & $3(3.0)$ & $2(1.9)$ & $4(4.1)$ & $11(2.7)$ \\
\hline Add bleach/chlorine & $2(2.0)$ & $6(6.1)$ & $2(1.9)$ & $5(5.1)$ & $15(3.7)$ \\
\hline Boil & $6(5.9)$ & $5(5.1)$ & $14(13.3)$ & $8(8.2)$ & $33(8.2)$ \\
\hline Other & $1(1.0)$ & $1(1.0)$ & $0(0.0)$ & $1(1.0)$ & $3(0.7)$ \\
\hline None & $91(89.2)$ & $84(84.8)$ & $87(82.9)$ & $80(81.6)$ & $342(84.7)$ \\
\hline Covered water storage vessels, $n(\%)$ & $82(80.4)$ & $84(84.8)$ & $86(81.9)$ & 76 (77.6) & $328(81.2)$ \\
\hline \multicolumn{6}{|l|}{ Main water supply, $n(\%)$} \\
\hline Continuous & $30(29.4)$ & $19(19.2)$ & $33(31.4)$ & $21(21.4)$ & $103(25.5)$ \\
\hline Sometimes interrupted & $72(70.6)$ & $80(80.8)$ & $72(68.6)$ & 77 (78.6) & $301(74.5)$ \\
\hline \multicolumn{6}{|l|}{ Improved toilet facility, $n$ (\%) } \\
\hline Unimproved & $8(7.8)$ & $6(6.1)$ & $8(7.6)$ & $3(3.1)$ & $25(6.2)$ \\
\hline Improved & 94 (92.2) & $93(93.9)$ & $97(92.4)$ & $95(96.9)$ & $379(93.8)$ \\
\hline \multicolumn{6}{|c|}{ Frequency of handwashing after using toilet, $n(\%)$} \\
\hline Never & $5(4.9)$ & $2(2.0)$ & $2(1.9)$ & $5(5.1)$ & $14(3.5)$ \\
\hline Rarely & $12(11.8)$ & $16(16.2)$ & $11(10.5)$ & $17(17.3)$ & $56(13.9)$ \\
\hline Often & $7(6.9)$ & $13(13.1)$ & $10(9.5)$ & $8(8.2)$ & $38(9.4)$ \\
\hline Always & $78(76.5)$ & $68(68.7)$ & $82(78.1)$ & $68(69.4)$ & $296(73.3)$ \\
\hline \multicolumn{6}{|l|}{ Child characteristics, $n(\%)$} \\
\hline $\begin{array}{l}\text { Diarrhea in primary study child in the } \\
\text { last } 7 \text { days }\end{array}$ & $20(19.6)$ & $23(23.2)$ & $22(21.0)$ & $20(20.4)$ & $85(21.0)$ \\
\hline \multicolumn{6}{|c|}{ Age of primary study child at baseline (years), $n$ (\%) } \\
\hline$<1$ & $42(41.2)$ & $38(38.4)$ & $40(38.1)$ & $35(35.7)$ & $155(38.4)$ \\
\hline $1-2$ & $37(36.3)$ & $34(34.3)$ & $41(39.0)$ & $36(36.7)$ & $148(36.6)$ \\
\hline $2-3$ & $23(22.5)$ & 27 (27.3) & 24 (22.9) & 27 (27.6) & $101(25.0)$ \\
\hline $\begin{array}{l}\text { Length/height-for-age } z \text {-score at } \\
\text { baseline, mean }( \pm S D)^{\star}\end{array}$ & $-1.25( \pm 1.23)$ & $-1.19( \pm 1.38)$ & $-1.44( \pm 1.12)$ & $-1.63( \pm 1.35)$ & $-1.38( \pm 1.28)$ \\
\hline
\end{tabular}


TABLE 1

Continued

\begin{tabular}{|c|c|c|c|c|c|}
\hline & Filter $(n=102)$ & Ceramic tablet $(n=99)$ & Safe storage $(n=105)$ & No intervention $(n=98)$ & Overall $(n=404)$ \\
\hline $\begin{array}{l}\text { Weight-for-age } z \text {-score at baseline, } \\
\text { mean }( \pm S D)^{*}\end{array}$ & $-0.21( \pm 1.11)$ & $-0.25( \pm 1.19)$ & $-0.42( \pm 1.19)$ & $-0.48( \pm 1.38)$ & $-0.34( \pm 1.22)$ \\
\hline $\begin{array}{l}\text { Height-for-weight } z \text {-score at baseline, } \\
\text { mean }( \pm S D)^{\star}\end{array}$ & $0.69( \pm 1.25)$ & $0.54( \pm 1.40)$ & $0.55( \pm 1.48)$ & $0.49( \pm 1.50)$ & $0.56( \pm 1.41)$ \\
\hline Stunted at baseline, $n(\%)^{\star}$ & $25(24.5)$ & $29(29.3)$ & $31(29.5)$ & $40(40.8)$ & $125(30.9)$ \\
\hline Underweight at baseline, $n(\%)^{\star}$ & $7(6.9)$ & $7(7.1)$ & $9(8.6)$ & $11(11.2)$ & $34(8.4)$ \\
\hline Wasted at baseline, $n(\%)^{\star}$ & $2(2.0)$ & $5(5.1)$ & $4(3.8)$ & $4(4.1)$ & $15(3.7)$ \\
\hline
\end{tabular}

water from the municipality had little to no detectable residual chlorine by the time it reached the user. ${ }^{34}$ Few households obtained drinking water from groundwater $(n=37,9.2 \%$ from springs and $n=11,2.7 \%$ from boreholes) or directly from surface water $(n=27,6.7 \%)$. Treatment of drinking water was rare $(n=62,15.3 \%)$, but most storage vessels were covered ( $n=328,81.2 \%$; Table 1). Although most caregivers of children in the youngest age-group (0-11 months) reported that their child was breastfed at the 3-month visits $(n=173 / 205$, $84.4 \%$ ), almost all also reported giving other milks and/or plain water ( $n=196 / 205,95.6 \%$ ), suggesting exclusive breastfeeding was highly uncommon. Breastfeeding was less common among the older children $(n=291 / 692,42.1 \%$ among ages $12-23$ months and $n=22 / 1,650,1.3 \%$ among ages $24+$ months).
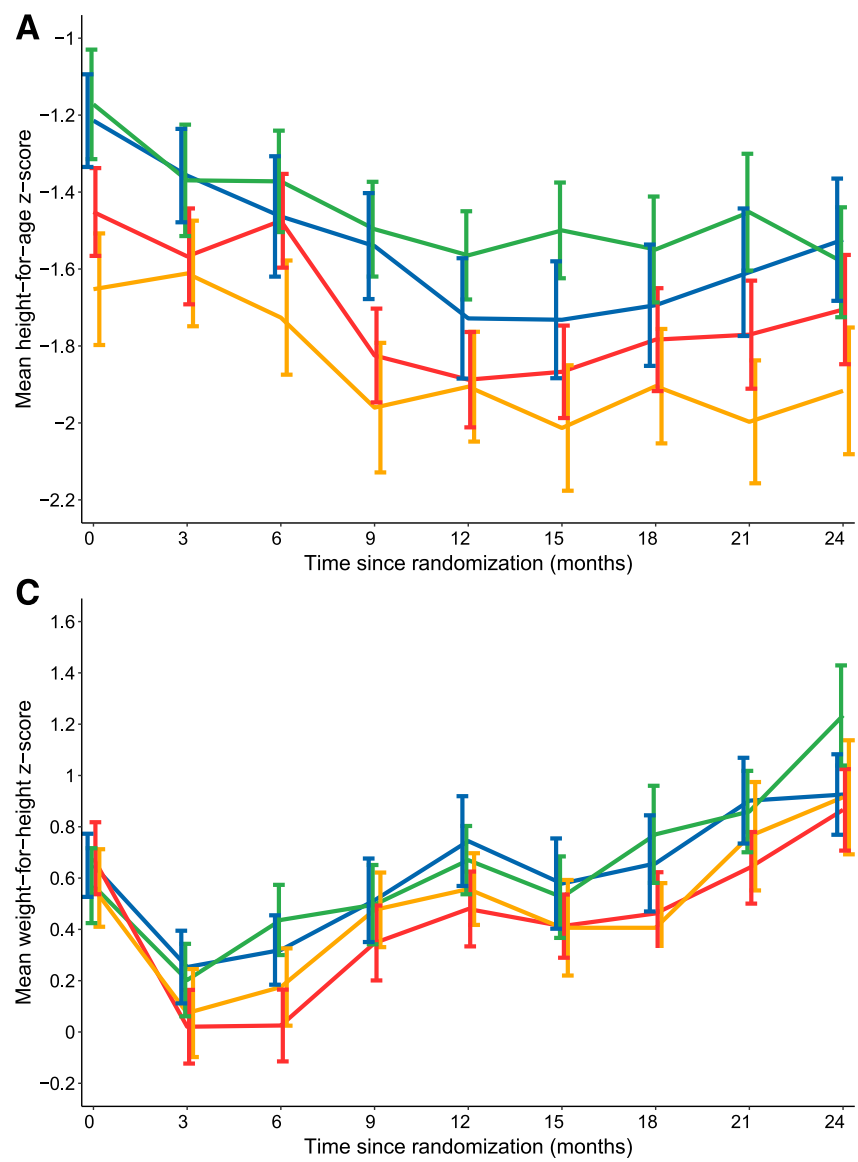

Baseline household characteristics were similar between intervention arms. However, children in the no intervention group were slightly older, and mean anthropometric z-scores were lower (Table 1). A total of 114 (28.2\%) household dropped out ( $n=57,14.1 \%$ in each year), such that 290 households completed the 24-month follow-up visit (Figure 1). Dropout was not significantly associated with randomization group $(P=0.6)$, but children who dropped out were younger, their anthropometric $z$-scores were lower at baseline, and their mothers were slightly less educated than children who completed follow-up (Supplemental Table S2). For example, 39\% $(n=44)$ of children who dropped out were stunted at baseline compared with $28 \%$ ( $n=81$ ) of children who completed follow-up.

Adherence. Participants randomized to one of the three intervention groups self-reported adherence data a median of

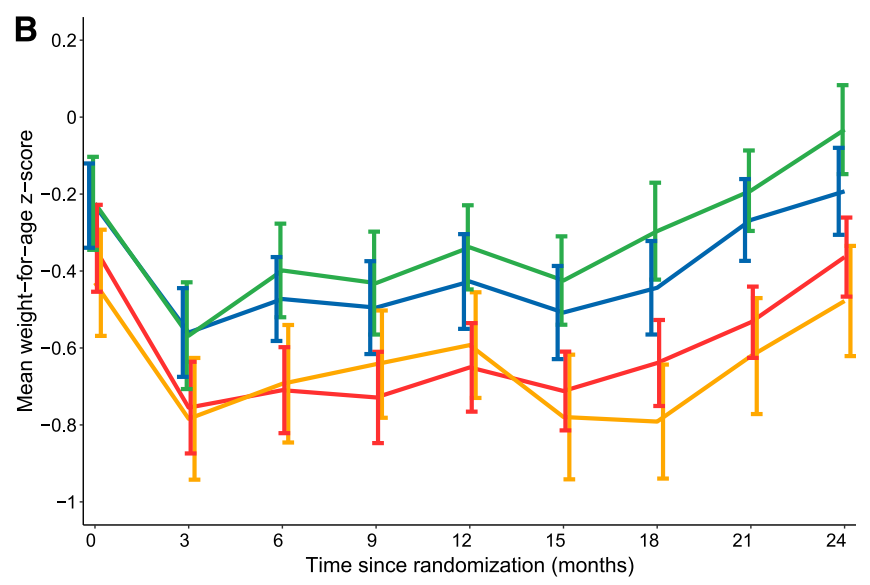

Filter

- Ceramic tablet

- Safe-storage container

- No intervention

FIGURE 1. Mean height-for-age (A), weight-for-age (B), and weight-for-height (C) z-score growth trajectories among 404 children. Error bars represent standard errors. This figure appears in color at www.ajtmh.org. 
19 times (interquartile range [IQR]: 16, 21) at monthly visits over 2 years of follow-up. At most of these visits, the participants reported that members of the household drank water from the intervention container 7 days per week $(88.3 \%, n=$ $4,552 / 5,121)$, and this proportion was higher among participants randomized to receive the ceramic tablet $(92.7 \%)$ than among participants randomized to receive the filter (85.6\%) or the safe storage container $(86.7 \%$; $P<0.0001)$. Participants reported that someone in the household drank water from the intervention container specifically during the previous day at $96.7 \%$ of visits ( $n=4,952 / 5,122)$, and this proportion did not differ by the intervention group $(P=0.2)$. The proportion drinking from the intervention container on the previous day was $90 \%$ or higher every month and increased on average by $2.6 \%(95 \% \mathrm{Cl}: 0.5,4.7)$ from baseline to 24 months. Participants reported refilling the intervention container a median of every 3 days (IQR: 3,4 ), almost exclusively by an adult woman $(96.7 \%, n=1,888 / 1,953)$ in the morning $(62.6 \%, n=1,223$ / $1,953)$ or at night $(23.1 \%, n=452 / 1,953)$.

The Smart Spout measured less intervention usage (Supplemental Figure S1). On an average day, $75.8 \%$ of participants used their interventions, including $71.5 \%$ in the ceramic filter group, $81.2 \%$ in the ceramic tablet group, and $81.4 \%$ in the safe storage container alone group. After households in the ceramic tablet group were switched to the filter intervention, use on an average day in this group dropped to $68.1 \%$. Consistent intervention use was less common; although on an average day $80.1 \%$ of households had used the intervention on at least 4 of the past 7 days, only $43.4 \%$ of households had used their intervention on each of the previous 7 days $(39.1 \%, 44.2 \%$, and $51.4 \%$ in the filter, tablet, and safe storage container groups, respectively; Supplemental Figure S1).

Caregivers reported that the primary study child most often drank water from the intervention container at $97.5 \%$ of visits. The primary study child additionally drank water from other sources or storage containers while at home at $18.2 \%$ ( $n=$ $934 / 5,122$ ) of monthly visits, primarily because caregivers forgot about the intervention $(n=858,91.9 \%)$, and rarely because the container was empty $(n=23,2.5 \%)$, the intervention was broken ( $n=12,1.3 \%)$, or they disliked the taste or smell of the water $(n=7,0.8 \%)$. The proportion of children drinking water from other sources did not change over the study period $(P=0.5)$, but was lower in the ceramic tablet group (9.8\%) than the filter $(22.9 \%)$ and safe storage container $(21.8 \%)$ groups $(P<0.0001)$.

Water quality. Intervention effects on water quality were previously reported. ${ }^{25-29}$ We evaluated the effect of the interventions in 150 drinking water samples taken at 0, 6, and 12 months from households that had a ceramic filter $(n=75)$ or tablet $(n=75)$. In summary, the mean total coliform concentrations in household drinking water before treatment by the silver-impregnated ceramic filter and tablet were 4,654 cfu/ $100 \mathrm{~mL}$ and 5,722 cfu/100 mL, respectively. The filters and tablets provided approximately 1.2 and 3 log reductions of total coliform bacteria in the treated drinking water, respectively. ${ }^{25}$ Only seven $(9.3 \%)$ water samples treated by the tablet had $1 \mathrm{cfu} / 100 \mathrm{~mL}$ or greater, and 30 (40.0\%) water samples treated by the silver-impregnated ceramic filter had 1 cfu/100 mL or greater. ${ }^{25}$

Anthropometry. At baseline, children in the first year of life had a mean HAZ of -0.79 (SD: 1.31) and WAZ of -0.01 (SD:
1.29). Children in the second and third years of life were further below the WHO growth standards with mean HAZ of -1.66 (SD: 1.11) and -1.77 (SD: 1.20), and WAZ of -0.47 (SD: 1.19) and -0.49 (SD: 0.94), respectively. Adjusting for age, children in the filter group were $0.42 z$-scores $(95 \% \mathrm{Cl}: 0.08,0.76)$ taller at baseline than children in the no intervention group (Supplemental Table S3). Similarly, children in the ceramic tablet (mean difference (MD): $0.46,95 \% \mathrm{Cl}: 0.12,0.80$ ) and safe storage container (MD: $0.21,95 \% \mathrm{Cl}$ : $-0.13,0.55)$ groups were taller than those in the no intervention group at baseline. WAZ were also higher in the intervention groups, but these differences were not statistically significant (Supplemental Table S3).

Mean growth trajectories of children in the four intervention groups are shown in Figure 1. Children in the filter, ceramic tablet, and safe storage container groups were taller than those in the no intervention group at all time points. Similar differences were observed for $\mathrm{WAZ}$ and $\mathrm{WHZ}$. The mean change over the two years of follow-up was $-0.28(S D=1.24)$ for $\triangle \mathrm{HAZ}, 0.05(\mathrm{SD}=0.99)$ for $\triangle \mathrm{WAZ}$, and $0.34(\mathrm{SD}=1.56)$ for $\triangle \mathrm{WHZ}$. Adjusting for age, there were no differences in $\triangle \mathrm{HAZ}, \triangle \mathrm{WAZ}$, or $\triangle \mathrm{WHZ}$ among children in the intervention groups compared with children in the no intervention group (Table 2). Similarly, there were no differences between the combined intervention (filter and ceramic tablet) and combined control (safe storage container and no intervention groups). Finally, there were no differences in $\triangle H A Z, \triangle W A Z$, or $\triangle W H Z$ when stratifying by age at baseline (Supplemental Table S4).

More than a quarter $(n=82,29.7 \%)$ of children were stunted after 2 years of follow-up. Children in the filter, ceramic tablet, and safe storage container groups had a lower risk of stunting after 2 years than those in the no intervention group, but these estimates were not statistically significant and likely reflect the large differences in prevalence in stunting at baseline, despite adjustment for age and HAZ at baseline (Supplemental Table S5). Only 11 and four children were underweight and wasted at 24 months, respectively, such that comparison across intervention groups for these secondary outcomes was not possible.

Diarrhea prevalence. The 7-day prevalence of diarrhea at baseline was $18.5 \%(n=23), 22.7 \%(n=23)$, and $21.6 \%(n=$ 30 ) among children in their first, second, and third years of life, respectively. There were no significant differences in diarrhea prevalence at baseline between intervention groups $(P=0.9)$. Diarrhea prevalence decreased over the 2 years of follow-up in all intervention groups (Figure 2). At 2 years of follow-up, $3.8 \%(n=11)$ of children reported diarrhea in the past 7 days. There were no significant differences in diarrhea prevalence between intervention groups Table 3 . The prevalence of diarrhea in the combined intervention group was 1.05 times $(95 \% \mathrm{Cl}: 0.73,1.50)$ the prevalence in the combined control group. In a secondary as-treated analysis, there were no differences in diarrhea prevalence between intervention groups (Table 2).

Enteric infections. For the analysis of enteric infections, we collected 2,654 stool samples quarterly from baseline to 2 years of follow-up and tested 1,670 samples from 0, 6, 12, 18, and 24 months. Valid qPCR results were available for at least one of the pathogens tested in 1,624 (97.2\%) stool samples. Children had on average 4.0 (SD: 1.42) stool samples tested. Diarrhea was reported in the previous 7 days for 139 (8.6\%) samples, and there was no difference in the proportion of 
TABLE 2

Effect of water treatment interventions on child growth among 288 children who completed 24 months of follow-up and had a baseline anthropometric measure

\begin{tabular}{|c|c|c|c|c|c|}
\hline Intervention & Number of children & $Z$-score at baseline, mean (SD) & $Z$-score at 24 months, mean (SD) & $\Delta Z$-score, mean (SD) & Mean $\Delta Z$-score difference, ${ }^{\star}(95 \% \mathrm{Cl})$ \\
\hline \multicolumn{6}{|l|}{ Height-for-age $z$-score } \\
\hline Filter & 70 & $-1.08(1.15)$ & $-1.42(1.05)$ & $-0.35(1.20)$ & $0.06(-0.29,0.40)$ \\
\hline Ceramic tablet & 69 & $-1.24(1.31)$ & $-1.53(1.12)$ & $-0.29(1.31)$ & $0.00(-0.35,0.35)$ \\
\hline Safe storage & 75 & $-1.44(1.13)$ & $-1.63(1.13)$ & $-0.19(1.16)$ & $0.11(-0.23,0.44)$ \\
\hline No intervention & 62 & $-1.60(1.39)$ & $-1.88(1.29)$ & $-0.28(1.30)$ & 0 \\
\hline Combined intervention & 139 & $-1.16(1.23)$ & $-1.48(1.08)$ & $-0.32(1.25)$ & $-0.03(-0.27,0.21)$ \\
\hline Combined control & 137 & $-1.51(1.25)$ & $-1.75(1.20)$ & $-0.23(1.22)$ & 0. \\
\hline \multicolumn{6}{|l|}{ Weight-for-age $z$-score } \\
\hline Filter & 70 & $-0.13(1.06)$ & $-0.19(0.95)$ & $-0.06(0.97)$ & $-0.08(-0.42,0.26)$ \\
\hline Ceramic tablet & 70 & $-0.22(1.21)$ & $-0.05(0.97)$ & $0.16(1.03)$ & $0.13(-0.21,0.46)$ \\
\hline Safe storage & 79 & $-0.40(1.14)$ & $-0.36(0.91)$ & $0.04(0.94)$ & $-0.04(-0.36,0.29)$ \\
\hline No intervention & 63 & $-0.52(1.26)$ & $-0.48(1.14)$ & $0.04(1.03)$ & 0 \\
\hline Combined intervention & 140 & $-0.17(1.13)$ & $-0.12(0.95)$ & $0.05(1.01)$ & $0.04(-0.19,0.27)$ \\
\hline Combined control & 142 & $-0.45(1.19)$ & $-0.41(1.02)$ & $0.04(0.97)$ & 0 \\
\hline \multicolumn{6}{|l|}{ Weight-for-height $z$-score } \\
\hline Filter & 68 & $0.64(1.23)$ & $0.93(1.29)$ & $0.29(1.33)$ & $-0.11(-0.65,0.43)$ \\
\hline Ceramic tablet & 68 & $0.63(1.44)$ & $1.17(1.60)$ & $0.54(1.75)$ & $0.13(-0.41,0.67)$ \\
\hline Safe storage & 74 & $0.62(1.33)$ & $0.80(1.34)$ & $0.18(1.44)$ & $-0.24(-0.77,0.29)$ \\
\hline No intervention & 60 & 0.49 (1.49) & $0.86(1.70)$ & $0.38(1.72)$ & 0 \\
\hline Combined intervention & 136 & $0.63(1.34)$ & $1.05(1.46)$ & $0.41(1.55)$ & $0.14(-0.23,0.51)$ \\
\hline Combined control & 134 & $0.56(1.40)$ & $0.83(1.51)$ & $0.27(1.57)$ & 0 \\
\hline
\end{tabular}

*Adjusted for age using cubic splines with 4 knots.

stools collected within 7 days of diarrhea across intervention arms $(P=0.7)$.

Enteric infections were highly common (Figure 3). Most stool samples ( $n=1,376,86.3 \%$ ) were positive for at least one of the eight enteric pathogens detected, and the mean number of pathogens detected per sample was 2.04 (SD: 1.53). Enteroaggregative Escherichia coli ( $n=746,46.0 \%)$, EHEC/ EPEC ( $n=658,43.2 \%)$, and adenovirus ( $n=549,35.8 \%)$ were the most commonly detected pathogens. There were no significant differences in enteric infection prevalence at baseline (Supplemental Figure S2).

The interventions had no statistically significant effects on the prevalence of any of the eight enteric pathogens between 6 and 24 months of follow-up (Figure 4). Adenovirus, Cryptosporidium, and Shigella/EIEC were more common in the

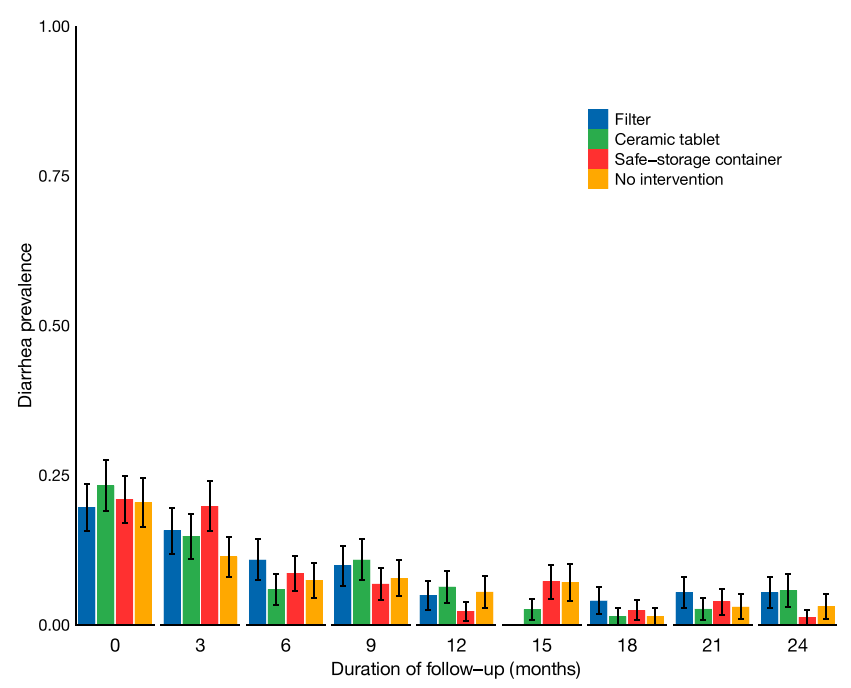

FIGURE 2. Seven-day prevalence of diarrhea by intervention group and duration of follow-up among 404 children. Error bars represent standard errors. This figure appears in color at www.ajtmh.org. intervention groups than in the no intervention group, but estimates were imprecise. Conversely, Giardia was less common in the filter group than in the no intervention group, but this difference was also not significant. There were no differences in the total number of pathogens detected between individual intervention groups (Supplemental Table S6). When combining intervention and control groups, there was a $20 \%$ higher prevalence of EAEC (PR: $1.20,95 \% \mathrm{Cl}: 1.06,1.36)$ in the intervention groups than in the control (Supplemental Table S6). The total number of pathogens detected was also $11 \%$ higher in the combined intervention group than in the combined control group (ratio of number of pathogens detected: 1.11, 95\% Cl: 1.02, 1.22).

In a secondary as-treated analysis, there were no differences in enteric pathogen prevalence between intervention groups, except that there was a higher frequency of EAEC in the combined intervention than in the combined control groups (Supplemental Table S7). Results were consistent in a sensitivity analysis in which samples tested in 2016 and 2017 were excluded, except that there was also a higher frequency of Cryptosporidium in the combined intervention than in the combined control groups (Supplemental Table S8).

\section{DISCUSSION}

Although the ceramic filters and MadiDrops significantly reduced the total coliform bacteria in treated water, the improvements in household drinking water quality did not translate to significant improvements in child growth. No differences were observed in $\triangle \mathrm{HAZ}, \triangle \mathrm{WAZ}$, or $\triangle \mathrm{WHZ}$ among children in the intervention groups compared with children in the no intervention group. Similarly, access to the silverimpregnated ceramic filter or tablet did not prevent enteric infections. Despite the high frequency of infections in this population, there were no statistically significant effects of the interventions on the prevalence of any of the eight enteric 


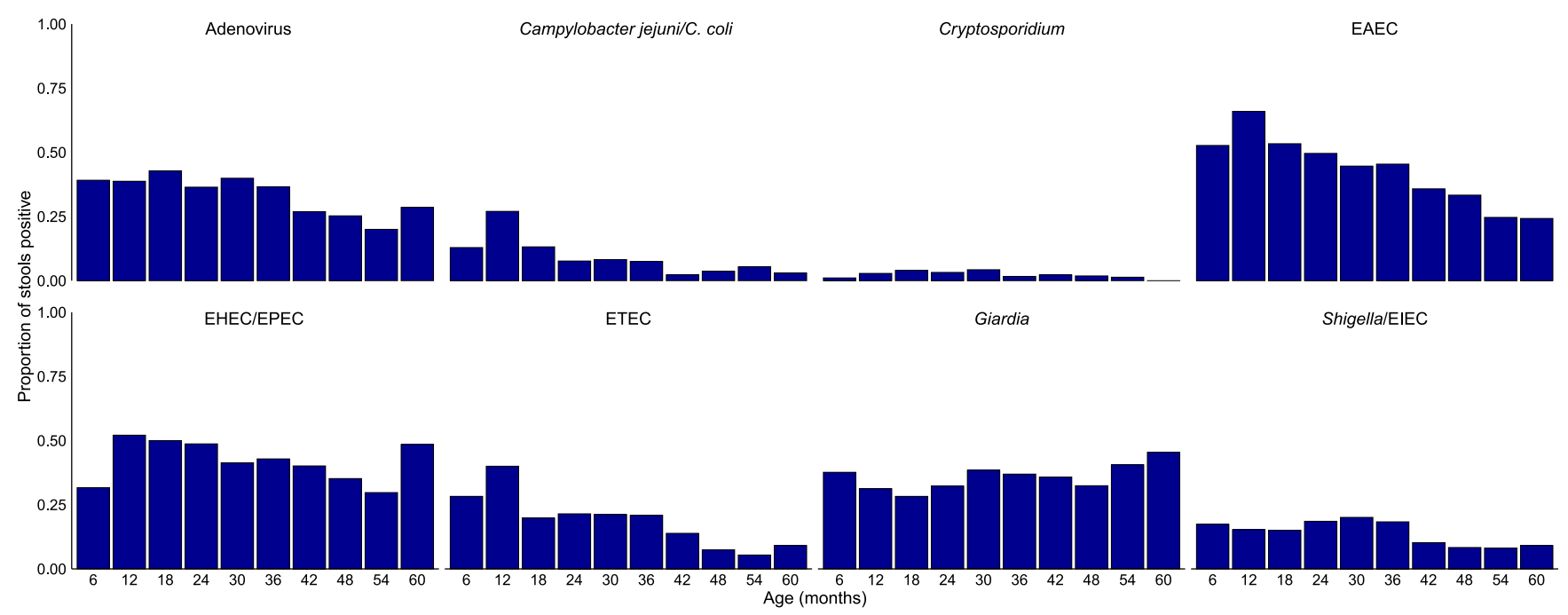

FIGURE 3. Prevalence of enteric pathogens by age among 394 children with at least one stool validly tested. E. coli $=$ Escherichia coli; EAEC $=$ enteroaggregative $E$. coli, EHEC = enterohemorrhagic $E$. coli, EIEC = enteroinvasive $E$. coli, EPEC: enteropathogenic $E$. coli, ETEC = enterotoxigenic E. coli. This figure appears in color at www.ajtmh.org.

pathogens or the total number of pathogens detected between 6 and 24 months of follow-up. The expected mechanism for the impact of drinking water interventions on linear growth is through a reduction in enteric infections. The lack of effect on linear growth may therefore be explained by no significant reductions in enteric infections.

\title{
Adenovirus
}

Campylobacter

Cryptosporidium

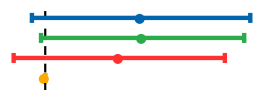

\author{
jejuni/C. coli
}

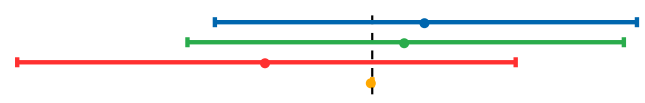

EAEC

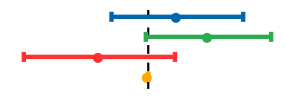

EHEC/EPEC

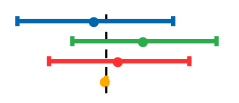

+ Filter

+ Ceramic tablet

+ Safe-storage container

+ No intervention

ETEC

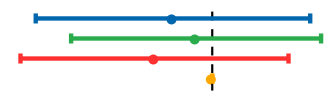

Giardia

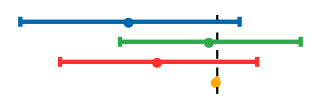

Shigella/EIEC

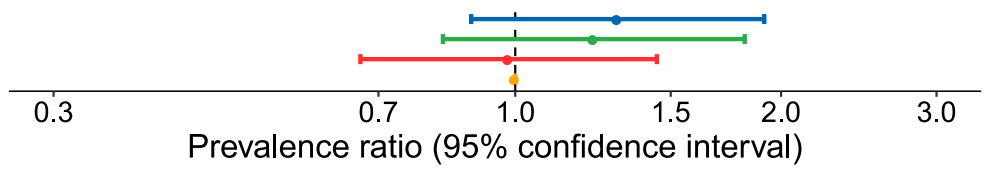

FIGURE 4. Effects of the silver-impregnated ceramic filter, silver-impregnated ceramic tablet, and safe storage water container on the prevalence of enteric infections compared with no intervention among 365 children with at least one stool validly tested after the baseline visit. $E$. coli $=$ Escherichia coli; $\mathrm{EAEC}=$ enteroaggregative $E$. coli, $\mathrm{EHEC}=$ enterohemorrhagic $E$. coli, EIEC = enteroinvasive $E$. coli, $\mathrm{EPEC}=$ enteropathogenic $E$. coli; $\mathrm{ETEC}=$ enterotoxigenic $E$. coli. This figure appears in color at www.ajtmh.org. 
TABLE 3

Intervention effects on 7-day prevalence of diarrhea at quarterly follow-up visits for 24 months among 388 children

\begin{tabular}{|c|c|c|c|c|c|c|}
\hline \multirow[b]{2}{*}{ Intervention } & \multicolumn{3}{|c|}{ Intention-to-treat analysis } & \multicolumn{3}{|c|}{ As-treated analysis } \\
\hline & $\begin{array}{l}\text { Number of } \\
\text { follow-up visits }\end{array}$ & $\begin{array}{l}\text { Diarrhea in the past } \\
7 \text { days, } n(\%)\end{array}$ & $\begin{array}{c}\text { Prevalence ratio* } \\
(95 \% \mathrm{Cl})\end{array}$ & $\begin{array}{l}\text { Number of } \\
\text { follow-up visits }\end{array}$ & $\begin{array}{l}\text { Diarrhea in the past } \\
\quad 7 \text { days, } n(\%)\end{array}$ & $\begin{array}{l}\text { Prevalence ratio* } \\
(95 \% \mathrm{Cl})\end{array}$ \\
\hline Filter & 643 & $46(7.2)$ & $1.17(0.70,1.96)$ & 490 & $39(8.1)$ & $1.14(0.67,1.94)$ \\
\hline No silver filter & - & - & - & 467 & $18(3.9)$ & $1.09(0.52,2.30)$ \\
\hline Ceramic tablet & 634 & $41(6.5)$ & $1.07(0.61,1.88)$ & 320 & $30(9.4)$ & $1.23(0.69,2.21)$ \\
\hline Safe storage & 688 & $46(6.7)$ & $1.13(0.69,1.84)$ & 688 & $46(6.7)$ & $1.13(0.69,1.84)$ \\
\hline No intervention & 598 & $36(6.1)$ & 1. & 598 & $36(6.1)$ & 1 \\
\hline Combined intervention $†$ & 1,277 & $87(6.9)$ & $1.05(0.73,1.50)$ & 810 & $69(8.5)$ & $1.10(0.75,1.61)$ \\
\hline Combined control & 1,286 & $82(6.4)$ & 1. & 1,286 & $82(6.4)$ & 1. \\
\hline
\end{tabular}

†For as-treated analysis, excludes the no silver filter group.

There was also no effect on diarrhea prevalence in both intention-to-treat and as-treated analyses. The cohort had low diarrhea rates at baseline that declined throughout the study, likely because of the children aging. Therefore, there may have been limited opportunity to interrupt transmission of diarrheaassociated pathogens.

The limited impact on both primary and secondary outcomes observed in this study could be attributed to several explanations. Children are exposed to enteric pathogens through a variety of transmission pathways including contaminated food and exposure to soil contaminated with animal feces. $^{35-37}$ Specifically, enteroaggregative E. coli and EPEC can be transmitted through contaminated food in addition to water, and adenovirus and Shigella/EIEC are primarily transmitted person-to-person. ${ }^{38-41}$ Preventing transmission only through pathways involving drinking water allows for children to still be exposed through these alternate pathways. In addition, the adherence data showed that all participants did not use their water intervention every day, suggesting that some children could have been exposed to pathogens from untreated drinking water sources. Furthermore, the quantity of water available may have been as or more important than quality because quantity determines how much is used for hygiene, and the volume of water used decreases substantially once water access is off-plot, ${ }^{42}$ which was common in this study. On the other hand, breastfeeding may have provided protection against enteric infections and reduced drinking water requirements for the youngest children across intervention groups. However, exclusive breastfeeding was rare, and breastfeeding did not eliminate exposure to potentially contaminated water in this setting. Finally, the interventions were implemented at the individual level rather than at the community level, which may be required to sufficiently limit pathogen contamination. ${ }^{43,44}$

The focus on objective outcomes, including anthropometric measures and enteric infections, was a strength of the study. Although participants were not masked to the intervention received, all laboratory analyses were blinded to the intervention group. The secondary outcome of caregiverreported diarrheal prevalence was potentially biased because the caregivers were not blinded to which intervention group they belonged to, which may have resulted in intervention households less likely to report diarrhea than control households. ${ }^{45}$ Objective detection of enteric pathogens helped to avoid recall bias and directly measured part of the causal pathway between the water treatment intervention and growth. ${ }^{46}$ Similarly, the objective adherence data measured through the Smart Spout improved our ability to characterize intervention usage, and, perhaps not surprisingly, objective measures of adherence were lower than the near-universal self-reported adherence.

This study was limited by the small study size and low diarrhea rates, which restricted our ability to detect significant effects of the interventions. Furthermore, the age range of enrolled children was relatively wide, which may have obscured effects in the youngest age-group that has the highest growth rates. Although age-specific effects were highly underpowered, the intervention effects were largest in this subgroup. The inconsistent adherence as measured by the Smart Spout was also a limitation, as high adherence to water quality interventions has been shown to be required for interventions to be effective in achieving gains in health outcomes. ${ }^{47}$ The changes of interventions over follow-up were limiting in that each group did not have the same device throughout the study, and the filters without silver were substantially less effective in treating drinking water than silver-impregnated ceramic tablets and filters. ${ }^{25}$ However, silver-impregnated ceramic tablets with $100 \%$ and $50 \%$ silver had similar rates of disinfection, suggesting that they should have had similar effectiveness. Because the primary analysis was intention-totreat, bias from intervention changes would be expected to be toward the null. Difference in height at baseline between intervention groups was also a limitation, but because the primary outcome was change in height, these baseline differences were accounted for in the analysis.

The results on child growth from this trial are consistent with those from several recent large intervention trials (WASH Benefits and SHINE), which were larger and tested more comprehensive WASH and nutrition interventions. ${ }^{8-10}$ Similar to this study, WASH Benefits Bangladesh, WASH Benefits Kenya, and SHINE showed that WASH interventions did not improve linear growth. ${ }^{8-10}$ The interventions in SHINE also did not reduce enteric infections. ${ }^{48}$ Furthermore, WASH Benefits Kenya ${ }^{9}$ and SHINE $^{10}$ found no impact on diarrhea, and diarrheal prevalence was reduced in all intervention arms of the WASH Benefits Bangladesh trial, except in the drinking water treatment alone arm. ${ }^{8}$ Importantly, these studies all tested POU water chlorination, which is a much more labor-intensive intervention than the ceramic filter and tablet tested here. The Smart Spout documented that adherence was higher for the ceramic tablet than for the filter, potentially because the tablet requires less user interaction. Demands on the user are an important design consideration affecting uptake. This study demonstrates that POU interventions that were less 
demanding of the user were still ineffective in reducing enteropathogen transmission. Therefore, our results support the consensus conclusion from the previous studies that more transformative interventions, including larger scale infrastructure projects, are likely necessary to prevent enteric infections and improve growth among children. ${ }^{43}$

Although this study and the WASH Benefits and SHINE trials did not show effectiveness to prevent enteric infections or growth stunting, several studies have shown that POU interventions reduce the incidence of diarrheal disease in diverse settings. ${ }^{16-18,49}$ Specifically, fabric filtration yielded a $48 \%$ reduction in cholera in a study in Bangladesh with 133,000 participants. In addition, silver-impregnated ceramic water filters were shown to reduce diarrheal prevalence in HIV-positive individuals in Limpopo, South Africa. ${ }^{15}$ However, these studies involved special populations that may have had higher adherence than families of healthy young children. Regardless, improving access to safe drinking water is important not only for the health impacts but also because it promotes dignity and protects the human right of access to safe drinking water. ${ }^{50}$

Despite their effectiveness in treating drinking water, the use of the silver-impregnated ceramic water filters and tablets did not reduce enteric infections or improve child growth in this trial. More comprehensive WASH interventions, potentially at the community level, that better prevent enteric infections are likely needed to demonstrate improvements in long-term child growth outcomes.

Received March 30, 2020. Accepted for publication June 19, 2020.

Published online August 24, 2020.

Note: Supplemental materials appears at www.ajtmh.org.

Acknowledgments: We thank A. Gaylord, N. Khuliso, S. Mammburu, K. McCain, C. Reynolds, E. Stinger, C. Kim, E. Lesmez, B. McCarty, L. Hill, C. Brown, M. Konathapally, N. Munonde, and O. Jones who performed baseline water quality analysis, and T. Singh, J. Ngobeni, L. Netshishivhe, R. Ngobeni, A. Hasani Hlongwane, M. Masilo Maponya, N. Ndiitwani Gogela, T. Mathode, and M. Ntwanano who supported the laboratory analyses and data management. In addition, we thank the community health works in Dzimauli who performed anthropometry measurements, collected stool samples, and administered household surveys.

Financial support: This work was supported by the Thrasher Research Fund grant (13923) to E. T. R. M.; the U.S. National Academies of Sciences and USAID grant (AID-OAA-A-11-00012) to P. O. B.; the National Research Foundation of South Africa grant (114725) to P. O. B.; the National Science Foundation grant (CBET-1438619) to J. A. S.; the National Institutes of Health, Fogarty International Center grant (D43TW009359) to R. L. G., E. T. R. M., J. N. E., and D. M. K.; and the National Institutes of Health, National Institute of Allergy and Infectious Diseases grant (K01Al130326) to E. T. R. M. Student effort was supported by the University of Virginia (UVA) Jefferson Public Citizens Program, the UVA Center for Global Health, and the National Institutes of Health, National Institute on Minority Health and Health Disparities grant (T37MD008659) to R. A. D.

Disclosures: J. A. S. is a cofounder, chairman of the board, and chief scientist of Silivhere Technologies, Inc. (formerly, MadiDrop, PBC), which produces the ceramic tablets included in this study. He also owns approximately $15 \%$ equity in the company.

Disclaimer: The opinions, findings, conclusions, or recommendations are those of the authors alone and do not necessarily reflect the views of NAS, USAID, the National Research Foundation of South Africa, the Thrasher Research Fund, NSF, or the NIH.

Authors' addresses: Courtney L. Hill, Department of Engineering Systems and Environment, University of Virginia, Charlottesville, VA, E-mail: clh023@gmail.com. Kelly McCain, Department of Engineering
Systems and Environment, University of Virginia, Charlottesville, VA and Department of Epidemiology, Emory University, Atlanta, GA, E-mail: kelly.mccain@emory.edu. Mzwakhe E. Nyathi, Department of Animal Science, University of Venda, Thohoyandou, South Africa, E-mail: emanuel.nyathi@univen.ac.za. Joshua N. Edokpayi, Department of Hydrology and Water Resources Mining and Environmental Geology, University of Venda, Thohoyandou, South Africa, E-mail: joshua.edokpayi@univen.ac.za. David M. Kahler, Center for Environmental Research and Education, Duquesne University, Pittsburgh, PA, E-mail: kahlerd@duq.edu. Darwin J. Operario, Division of Infectious Diseases and International Health, University of Virginia, Charlottesville, VA, E-mail: do2s@virginia.edu. David D. J. Taylor, Department of Civil and Mineral Engineering, University of Toronto, Toronto, Canada, E-mail: davidd.taylor@utoronto.ca. Natasha C. Wright, Department of Mechanical Engineering, University of Minnesota Twin Cities, Minneapolis, MN, E-mail: wrigh677@umn.edu. James A. Smith, Department of Civil and Environmental Engineering, University of Virginia, Charlottesville, VA, E-mail: jas9e@virginia.edu. Richard L. Guerrant, Department of Infectious Diseases, University of Virginia, Charlottesville, VA, E-mail: rlg9a@virginia.edu. Amidou Samie and Pascal O. Bessong, Department of Microbiology, University of Venda, Thohoyandou, South Africa, E-mails: samie.amidou@ univen.ac.za and bessong@univen.ac.za. Rebecca A. Dillingham, Centre for Global Health, Charlottesville, VA, E-mail: rd8v@ hscmail.mcc.virginia.edu. Elizabeth T. Rogawski McQuade, Department of Public Health Sciences, University of Virginia School of Medicine, Charlottesville, VA and Division of Infectious Diseases and International Health, University of Virginia School of Medicine, Charlottesville, VA, E-mail: etr5m@virginia.edu.

This is an open-access article distributed under the terms of the Creative Commons Attribution (CC-BY) License, which permits unrestricted use, distribution, and reproduction in any medium, provided the original author and source are credited.

\section{REFERENCES}

1. Korpe PS, Petri WA, 2012. Environmental enteropathy: critical implications of a poorly understood condition. Trends $\mathrm{Mol}$ Med 18: 328-336.

2. Rogawski ET et al., 2018. Use of quantitative molecular diagnostic methods to investigate the effect of enteropathogen infections on linear growth in children in low-resource settings: longitudinal analysis of results from the MAL-ED cohort study. Lancet Glob Health 6: e1319-e1328.

3. del Carmen Casanovas M et al., 2013. Multi-sectoral interventions for healthy growth. Matern Child Nutr 9 (Supp/ 2): 46-57.

4. World Health Organization, - Global Nutrition Targets 2025: Stunting Policy Brief. Geneva, Switzerland: WHO. Available at: http://www.who.int/nutrition/publications/globaltargets2025 policybrief_stunting/en/. Accessed January 24, 2020.

5. de Onis M, Blössner M, Borghi E, 2012. Prevalence and trends of stunting among pre-school children, 1990-2020. Public Health Nutr 15: 142-148.

6. de Onis M, Dewey KG, Borghi E, Onyango AW, Blössner M, Daelmans B, Piwoz E, Branca F, 2013. The World Health Organization's global target for reducing childhood stunting by 2025: rationale and proposed actions. Matern Child Nutr 9 (Suppl 2): 6-26.

7. Victora CG, Adair L, Fall C, Hallal PC, Martorell R, Richter L, Sachdev HS; Maternal and Child Undernutrition Study Group, 2008. Maternal and child undernutrition: consequences for adult health and human capital. Lancet Lond Engl 371: 340-357.

8. Luby SP et al., 2018. Effects of water quality, sanitation, handwashing, and nutritional interventions on diarrhoea and child growth in rural Bangladesh: a cluster randomised controlled trial. Lancet Glob Health 6: e302-e315.

9. Null $\mathrm{C}$ et al., 2018. Effects of water quality, sanitation, handwashing, and nutritional interventions on diarrhoea and child growth in rural Kenya: a cluster-randomised controlled trial. Lancet Glob Health 6: e316-e329.

10. Humphrey $\mathrm{JH}$ et al., 2019. Independent and combined effects of improved water, sanitation, and hygiene, and improved complementary feeding, on child stunting and anaemia in rural Zimbabwe: a cluster-randomised trial. Lancet Glob Health 7: e132-e147. 
11. Humphrey $\mathrm{JH}, 2009$. Child undernutrition, tropical enteropathy, toilets, and handwashing. Lancet Lond Engl 374: 1032-1035.

12. Mellor JE, Smith JA, Learmonth GP, Netshandama VO, Dillingham RA, 2012. Modeling the complexities of water, hygiene, and health in Limpopo province, South Africa. Environ Sci Technol 46: 13512-13520.

13. Levy K, Nelson KL, Hubbard A, Eisenberg JNS, 2008. Following the water: a controlled study of drinking water storage in northern coastal Ecuador. Environ Health Perspect 116: 1533-1540.

14. Günther I, Schipper Y, 2013. Pumps, germs and storage: the impact of improved water containers on water quality and health. Health Econ 22: 757-774.

15. Abebe LS, Smith JA, Narkiewicz S, Oyanedel-Craver V, Conaway M, Singo A, Amidou S, Mojapelo P, Brant J, Dillingham R, 2014. Ceramic water filters impregnated with silver nanoparticles as a pointof-use water-treatment intervention for HIV-positive individuals in Limpopo province, South Africa: a pilot study of technological performance and human health benefits. J Water Health 12: 288-300.

16. Colwell RR et al., 2003. Reduction of cholera in Bangladeshi villages by simple filtration. Proc Natl Acad Sci U S A 100: 1051-1055.

17. Clasen TF, Brown J, Collin S, Suntura O, Cairncross S, 2004. Reducing diarrhea through the use of household-based ceramic water filters: a randomized, controlled trial in rural Bolivia. Am J Trop Med Hyg 70: 651-657.

18. Brown J, Sobsey MD, Loomis D, 2008. Local drinking water filters reduce diarrheal disease in Cambodia: a randomized, controlled trial of the ceramic water purifier. Am J Trop Med Hyg 79: 394-400.

19. Oyanedel-Craver VA, Smith JA, 2008. Sustainable colloidalsilver-impregnated ceramic filter for point-of-use water treatment. Environ Sci Technol 42: 927-933.

20. Kallman Erin N, Oyanedel-Craver Vinka A, Smith James A, 2011. Ceramic filters impregnated with silver nanoparticles for point-of-use water treatment in rural Guatemala. J Environ Eng 137: 407-415.

21. Ren D, Colosi LM, Smith JA, 2013. Evaluating the sustainability of ceramic filters for point-of-use drinking water treatment. Environ Sci Technol 47: 11206-11213.

22. Ehdaie B, Krause C, Smith JA, 2014. Porous ceramic tablet embedded with silver nanopatches for low-cost point-of-use water purification. Environ Sci Technol 48: 13901-13908.

23. Ehdaie B, Rento CT, Son V, Turner SS, Samie A, Dillingham RA, Smith JA, 2017. Evaluation of a silver-embedded ceramic tablet as a primary and secondary point-of-use water purification technology in Limpopo province, S. Africa. PLoS One 12: e0169502.

24. Kahler DM, Koermer NT, Reichl AR, Samie A, Smith JA, 2016. Performance and acceptance of novel silver-impregnated ceramic cubes for drinking water treatment in two field sites: Limpopo province, South Africa and Dodoma region, Tanzania. Water 8: 95.

25. Hill C et al., 2020. Technological performance of safe water storage containers, ceramic water filters, and MadiDrops in a 400-family cohort study in rural South Africa. Environ Sci Technol (In prep).

26. McCarty B et al., 2017. Associations Between Drinking Water Source, Enteropathogen Prevalence in Child Stools, and Child Growth in rural communities in Limpopo Province, South Africa. Presented at the UNC Water and Health Conference - Poster Session, Drinking Water Quality Category. Chapel Hill, NC.

27. Hill $C$ et al., 2016. Effectiveness of Point-of-use Water Treatment Technologies to Prevent Stunting Among Children in Limpopo, South Africa. Presented at the: UNC Water and Health Conference - Verbal Presentations, Water Treatment Session. Chapel Hill, NC.

28. Hill C et al., 2018. Technological Field Performance of a New Point-of-use Water Treatment Technology in a Randomized Control Trial in Limpopo, South Africa. Presented at the: UNC Water and Health Conference - Verbal Presentations, Wash Interventions (III) Session. Chapel Hill, NC.

29. Hill C et al., 2019. Impact of Low-cost Point-of-use Water Treatment Technologies on Enteric Infections and Linear Growth among Children in Limpopo, South Africa. Presented at the American Society of Tropical Medicine and Hygiene Annual Meeting Verbal Presentations, Water, Sanitations, Hygiene and Environmental Health Session. Fort Washington, MD: National Harbor.

30. WHO, 2017. Guidelines for Drinking-Water Quality, 4th Edition, Incorporating the 1st Addendum. Geneva, Switzerland: World Health Organization. Available at: http://www.who.int/water_ sanitation health/publications/drinking-water-quality-guidelines4-including-1st-addendum/en/. Accessed January 24, 2020.

31. Liu J et al., 2016. Optimization of quantitative PCR methods for enteropathogen detection. PLOS ONE 11: e0158199. Available at: https://doi.org/10.1371/journal.pone.0158199.

32. Liu $\mathrm{J}$ et al., 2014. Development and assessment of molecular diagnostic tests for 15 enteropathogens causing childhood diarrhoea: a multicentre study. Lancet Infect Dis 14: 716-724.

33. World Health Organization, 2018. WHO Child Growth Standards: Methods and Development. Geneva, Switzerland: WHO. Available at: https://www.who.int/childgrowth/standards/ technical_report/en/. Accessed January 24, 2020.

34. Edokpayi J et al., 2018. Challenges to sustainable safe drinking water: a case study of water quality and use across seasons in rural communities in Limpopo province, South Africa. Water 10: 159.

35. Penakalapati G, Swarthout J, Delahoy MJ, McAliley L, Wodnik B, Levy K, Freeman MC, 2017. Exposure to animal feces and human health: a systematic review and proposed research priorities. Environ Sci Technol 51: 11537-11552.

36. Medgyesi D, Sewell D, Senesac R, Cumming O, Mumma J, Baker KK, 2019. The landscape of enteric pathogen exposure of young children in public domains of low-income, urban Kenya: the influence of exposure pathway and spatial range of play on multi-pathogen exposure risks. PLoS Negl Trop Dis 13: e0007292.

37. Wang $Y$ et al., 2017. Multipathway quantitative assessment of exposure to fecal contamination for young children in lowincome urban environments in Accra, Ghana: the SaniPath analytical approach. Am J Trop Med Hyg 97: 1009-1019.

38. Killackey SA, Sorbara MT, Girardin SE, 2016. Cellular aspects of Shigella pathogenesis: focus on the manipulation of host cell processes. Front Cell Infect Microbiol 6: 38.

39. Hebbelstrup Jensen B, Olsen KEP, Struve C, Krogfelt KA, Petersen AM, 2014. Epidemiology and clinical manifestations of enteroaggregative Escherichia coli. Clin Microbiol Rev 27: 614-630.

40. Evans DJ, Evans DG, 1996. Escherichia coli in diarrheal disease. Baron S, ed. Medical Microbiology, 4th edition. Galveston, TX: University of Texas Medical Branch at Galveston. Available at: http://www.ncbi.nlm.nih.gov/books/NBK7710/.

41. Cheng $\mathrm{J}$ et al., 2016. Epidemiology and transmission characteristics of human adenovirus type 7 caused acute respiratory disease outbreak in military trainees in east China. Am J Transl Res 8: 2331-2342.

42. Howard G, Bartram J, Water S; World Health Organization, 2003. Domestic Water Quantity, Service Level and Health. Geneva, Switzerland: World Health Organization.

43. Pickering AJ et al., 2019. The WASH benefits and SHINE trials: interpretation of WASH intervention effects on linear growth and diarrhoea. Lancet Glob Health 7: e1139-e1146.

44. Cumming $O$ et al., 2019. The implications of three major new trials for the effect of water, sanitation and hygiene on childhood diarrhea and stunting: a consensus statement. BMC Med 17: 173.

45. Wood L, Egger M, Gluud LL, Schulz KF, Jüni P, Altman DG, Gluud C, Martin RM, Wood AJG, Sterne JAC, 2008. Empirical evidence of bias in treatment effect estimates in controlled trials with different interventions and outcomes: meta-epidemiological study. BMJ 336: 601-605.

46. Brown J, Cumming O, 2020. Stool-based pathogen detection offers advantages as an outcome measure for water, sanitation, and hygiene trials. Am J Trop Med Hyg 102: 260-261.

47. Brown J, Clasen T, 2012. High adherence is necessary to realize health gains from water quality interventions. PLoS One 7: e36735.

48. Wolf $J$ et al., 2014. Systematic review: assessing the impact of drinking water and sanitation on diarrhoeal disease in low- and middle-income settings: systematic review and meta-regression. Trop Med Int Health 19: 928-942.

49. Leahy C, Winterford K, Nghiem T, Kelleher J, Leong L, Willetts J, 2017. Transforming gender relations through water, sanitation, and hygiene programming and monitoring in Vietnam. Gend Dev 25: 283-301. 